\title{
Review
}

\section{Nitric oxide and Drosophila development}

\author{
Grigori Enikolopov ${ }^{\star, 1}$, Julian Banerji ${ }^{1}$ and Boris Kuzin ${ }^{1}$ \\ ${ }^{1}$ Cold Spring Harbor Laboratory Cold Spring Harbor, NY 11724, USA \\ * corresponding author: Grigori Enikolopov, Ph.D., Cold Spring Harbor \\ Laboratory, Cold Spring Harbor, New York 11724, USA. tel: (516) 367-8316; \\ fax: (516) 367-6805; e-mail: enik@cshl.org
}

Received 14.6.99; revised 19.8.99; accepted 19.8.99

Edited by P. Nicotera

\begin{abstract}
Mechanisms controlling the transition of precursor cells from proliferation to differentiation during organism development determine the distinct anatomical features of tissues and organs. NO may mediate such a transition since it can suppress DNA synthesis and cell proliferation. Inhibition of NOS activity in the imaginal discs of Drosophila larvae results in hypertrophy of tissues and organs of the adult fly, whereas ectopic overexpression of NOS has the reciprocal, hypotrophic, effect. Furthermore, NO production is crucial for the establishment of ordered neuronal connections in the visual system of the fly, indicating that NO affects the acquisition of the differentiated phenotype by the neural tissue. Increasing evidence points to a broad role that NO may play in animal development by acting as an essential negative regulator of precursor cell proliferation during tissue and organ morphogenesis.
\end{abstract}

Keywords: nitric oxide; drosophila; differentiation; synaptogenesis; organ development

Abbreviations: APF, after puparium formation; BrdU, 5-bromodeoxyuridine; cGMP, $3^{\prime}<^{\prime} \psi \theta \psi \lambda \iota \psi \gamma \nu \alpha v \omega \sigma i v \varepsilon \mu \omega v \omega \pi \hbar \omega \sigma \pi \hbar \alpha \tau \varepsilon$. . $\Delta \Pi \nabla \because \operatorname{vi} \psi \omega \tau \imath v \alpha \mu 1 \delta \varepsilon \alpha \delta \varepsilon v i v \varepsilon \delta 1 v v \psi \lambda \varepsilon \omega \tau 1 \delta \varepsilon \pi \hbar \omega \sigma \pi \hbar \alpha \tau \varepsilon . \therefore \Omega \Sigma:$ $v \iota \tau \rho \imath \psi \omega \xi 1 \delta \varepsilon \sigma \theta v \tau \hbar \alpha \sigma \varepsilon . \therefore \varrho \beta \because \rho \varepsilon \tau 1 v \omega \beta \lambda \alpha \sigma \tau \omega \mu \alpha$

Organ and tissue development require a tightly controlled program of cell proliferation followed by growth arrest and differentiation and, often, programmed cell death. The balance between the number of cell divisions and the extent of subsequent programmed cell death determines the final size of a tissue or an organ (reviewed $\mathrm{in}^{1-3}$ ). Although much of the cellular machinery that controls cell division per se is well understood (reviewed $\mathrm{in}^{4-8}$ ) less is known about the signals that cause discrete groups of cells within organs to stop dividing upon reaching an appropriate cell number. These signals should relate cell cycle progression to information about the size of a domain of adjacent cells, and they probably involve some as yet undetermined inter- and intracellular second messenger molecules. These messen- gers might include multifunctional signaling molecules that would couple together several events, such as cessation of cell cycle progression, implementation of programmed cell death, and acquisition of specific traits that define a differentiated tissue.

Nitric oxide (NO) is a versatile diffusible second messenger implicated in numerous physiological functions in mammals, ranging from dilation of blood vessels and muscle relaxation to immune responses and potentiation of synaptic transmission (reviewed $\mathrm{in}^{9-12}$ ). It has also been shown to affect gene expression at the level of transcription $^{13-16}$ or translation. ${ }^{17-19} \mathrm{NO}$ is produced by nitric oxide synthase (NOS) in almost all cell types. Various isoforms of NOS are expressed throughout animal development, marking characteristic steps in tissue differentiation. ${ }^{20}$ Recent evidence indicates that NO may be an important player in the program of development, directing the transition out of the proliferating state to differentiation and affecting the acquisition of a differentiated phenotype.

Studies on Drosophila in particular have been useful in revealing the importance of $\mathrm{NO}$ in organ development and tissue differentiation. NO is produced at high levels in imaginal discs at the end of the larval stage and acts as an essential negative regulator of cell proliferation: manipulation of NOS activity in the developing larvae affects the size of the adult fly's organs. ${ }^{21}$ The morphogenic regulation by $\mathrm{NO}$ can be further evidenced at later points in development, being necessary for the proper development of the visual system of the fly, affecting synaptogenesis and the formation of retinal projection pattern. ${ }^{22}$

This review describes the NOS locus of Drosophila and the expression pattern of DNOS, discusses the data on the role of $\mathrm{NO}$ in cell proliferation and synapse formation in the developing fly, and considers evidence that NO has a conserved function in other developmental systems.

\section{DNOS locus}

The gene for Drosophila NO synthase is located on the second chromosome at cytological position 32B. This locus codes for a family of transcripts which may produce several NOS-related proteins. DNOS1 cDNA was originally cloned from a Drosophila head cDNA library using a fragment of the rat neuronal NOS gene as a probe. ${ }^{23}$ Since that time, several attempts to clone putative orthologs of mammalian endothelial and inducible forms of NOS from cDNA or genomic libraries have not revealed any other loci that would code for NOS-like enzymes (Stasiv, Regulski, Tully and Enikolopov, unpublished). However, an extended family of transcripts within the DNOS locus has been identified. These transcripts have different 5 '-ends, use alternative splice sites, and code for a family of NOS-related proteins. DNOS1 represents the major RNA isoform of NOS in Drosophila cells and codes for protein of 1350 amino acids which bears a strong resemblance to all 
three NOS isoforms from mammals (43, 40 and 39\% amino acid identity to rat neuronal, bovine endothelial, and mouse inducible isoforms of NOS, respectively) with a central portion showing $61 \%$ identity to the rat neuronal isoform.

The deduced DNOS1 protein contains all determinants which are crucial for NOS activity, such as regions for binding FMN, FAD, NADPH, tetrahydrobiopterin, heme, and calmodulin, and a consensus site for phosphorylation by cAMP-dependent protein kinase. At the same time, Drosophila NOS protein lacks the PDZ domain which is crucial for association of mammalian neuronal NOS with PDZ domains of other proteins such as PSD-95, $\alpha 1$ synthropin $^{24}$ and CAPON. ${ }^{25}$ The first 200 amino acids of DNOS1 show no obvious similarity to any of the known forms of NOS. This region contains a long stretch of glutamine residues which are found in many Drosophila, and some vertebrate, proteins and have been implicated in the formation of protein-protein contacts. ${ }^{26,27}$ DNOS1 cDNA, when expressed in cultured cells, produces a $150 \mathrm{kD}$ polypeptide which can efficiently generate NO. This production of $\mathrm{NO}$ is dependent on calcium, calmodulin, and terahydrobiopterin, as reported for the neuronal NOS of mammals.

Molecular characterization of the DNOS locus shows that transcribed sequences are dispersed over a minimum of $40 \mathrm{~kb}$ of DNA and consist of at least 20 exons (Stasiv, Regulski, Tully and Enikolopov, unpublished). The locus gives rise to at least eight isoforms of RNA and four different forms of proteins, one of which is DNOS1 protein, the major enzymatically active form of NOS in the fly. Interestingly, two of these alternate isoforms encode truncated proteins having no apparent enzymatic activity but which can inhibit the activity of DNOS1 in cotransfection assays (Stasiv and Enikolopov, unpublished). These proteins may act as dominant negative regulators of NOS activity in vivo, perhaps by disrupting homodimerization of DNOS1. Transgenic flies which express these various isoforms have been generated (Regulski, Stasiv, Tully and Enikolopov, unpublished) and may provide additional insights into the developmental role of different DNOSrelated proteins.

\section{Expression of DNOS during development}

Most of what we know about the expression and distribution of DNOS in developing Drosophila comes from the studies of NADPH-diaphorase staining of embryos and larvae. The biochemical properties of NOS and the NADPH-diaphorase activity have been well characterized in Drosophila, honeybee and locust. ${ }^{28-31}$ These studies suggest that in insects, as has been rigorously demonstrated in mammalian systems, the identical enzyme is responsible for both NOS activity and NADPH-diaphorase staining after fixation. These data are corroborated by in situ hybridization of imaginal discs with the DNOS1 probe (Kuzin, Regulski, Stasiv and Enikolopov, unpublished).

There is no indication of cellular NADPH-diaphorase staining in embryos prior to stage $15 .^{31}$ In stage 15 embryos, a row of segmentally repeated NADPH-diaphorase-positive cells, presumably of neuronal origin, appear near the midline of the ventral nerve cord (VNC); however, this staining disappears at later stages. The first larval instar shows NADPH-diaphorase-positive interneurons in the brain and motorneurons in the VNC (Figure 1). As the larvae progress to the second instar stage, the staining intensity and the number of NADPH-diaphorase-positive interneurons in the brain and motoneurons in the VNC increase and, in addition, staining appears in the interneurons of the VNC and in the cellular projections from the brain into the VNC. In the third instar, the number and intensity of NADPH-diaphorase-positive neurons in the brain continue to rise. In addition, cells along the midline of the VNC which is composed of both neurons and glia, are strongly stained. Very strong NADPH-diaphorase staining

L I

L II

ring gland

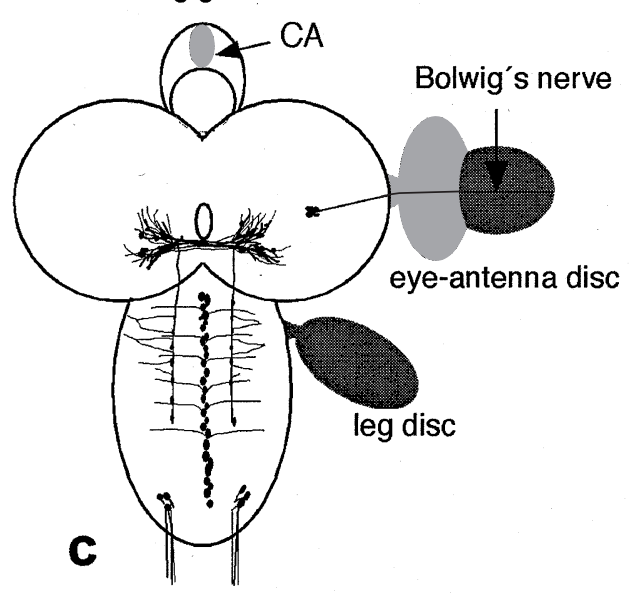

Figure 1 Schematic drawing of NADPH-diaphorase-positive cells of development Drosophila larvae (from Wildemann and Bicker). ${ }^{31}$ (a) First larval instar showing NADPH-diaphorase-positive interneurons in the brain and motoneurons in the VNC. (b) In the second instar, the staining intensity and the number of interneurons stained in the brain increase. Cellular projections from the brain into the VNC are also stained. (c) NADPH-diaphorase staining in the CNS and imaginal discs of the third instar larvae. Strong staining is present in the Bolwig's nerve (the larval optic nerve) and in the region of the ring gland corresponding to the corpus allatum (CA) 
can also be observed in the Bolwig's nerve, the optic nerve of the larvae, and in the region of the ring gland, a component of the endocrine system which regulates metamorphosis.

A dramatic increase in NADPH-diaphorase staining is observed in imaginal discs of the third instar. Imaginal discs, specialized groups of undifferentiated epithelial cells which later give rise to the epidermal structures of the adult fly, are formed in the first larval instar as integuments of the larval epidermis. ${ }^{32}$ Disc cells divide rapidly throughout larval development, cease proliferating at the end of the third instar period and in early pupae, and undergo dramatic changes during metamorphosis, eventually differentiating into the organs of the adult fly (legs, wings, eyes, halteres, genitalia). NADPH-diaphorase staining is quite weak in the young imaginal discs of the third instar and gradually increases as development proceeds. In late third instar larvae and early pupae, a highly specific pattern of very intense staining is evident in all imaginal discs and also in the imaginal rings and histoblasts. ${ }^{21,31}$ For instance, in the leg imaginal disc, NADPH-diaphorase staining is seen at the very beginning of the third instar and is confined to the center of the disc. As the discs mature, diaphorase staining is more apparent and at the end of the third instar period, it is present in all of the concentric rings of epithelial folding of the disc. Later in development, when the discs begin to evert in the prepupae, diaphorase staining of the forming leg becomes less intense. At $2-4 \mathrm{~h}$ after puparium formation, NADPH-diaphorase staining is seen in the presumptive tibia, first and second tarsal segments, and the proximal part of the fifth tarsal segment of the forming leg (see also Figure 3). Staining is much weaker in the third and fourth segments, and areas of staining are distributed throughout the regions of presumptive femur, coxa, and body wall. Similarly, highly reproducible patterns of intense staining are seen at the end of the third instar in the wing, the eye, the haltere, and the genital imaginal discs, as well as in the imaginal rings and histoblasts. This staining gradually decreases in a specific spatial pattern during pupal development.

After pupariation, very strong NADPH-diaphorase staining is observed in the brain in the regions of lamina and medulla of the optic lobe, where the synapses of the visual system are being formed. ${ }^{22}$ In the adult Drosophila, NOS expression is mostly confined to the brain, ${ }^{33-35}$ with weak NADPH-diaphorase staining being evident throughout the organs of the fly. Both NADPH-diaphorase and antibody staining suggest various levels of DNOS expression in different parts of the brain. The most abundant expression appears in (1) the antennal lobes of the olfactory system, (2) the fan-shaped body of the central complex and (3) the layer of medulla in the visual system. Intermediate to low levels of NOS expression include large parts of the neuropil of the central brain as well as the lobula and lamina of the visual system. The mushroom bodies, which are implicated in certain forms of learning and memory, display very low levels of NADPH-diaphorase activity and NOS immunoreactivity $^{34}$ (and Regulski and Tully, unpublished).

Together, the NADPH-diaphorase staining patterns of developing Drosophila indicate that in many cases NOS expression marks tissues that are differentiating, and neurons that are ready to establish synaptic contacts, suggesting that NO production may be involved both in the exit of cells from the proliferative phase, and in synapotogenesis in the developing nervous system.

\section{NO and the transition from proliferation to differentiation}

$\mathrm{NO}$ is a very effective inhibitor of cell proliferation. When chemical compounds that can release NO are added to cultured mammalian cells, DNA synthesis and cell division are suppressed. ${ }^{36-38}$ This inhibition may affect various phases of the cell cycle: NO donors inhibit progression through Sphase, ${ }^{39}$ suppress phosphorylation of pRb by cycle dependent kinases, ${ }^{40}$ induce $p 53^{41-43}$ and lead to an accumulation of a fraction of cells in the G2 phase. ${ }^{44,45}$ Thus, exogenously added NO acts as a potent antiproliferative agent. Recent data indicate that the antiproliferative properties of endogenously produced NO are employed by the developing organism to control cell proliferation during tissue differentiation and organ development.

Developing Drosophila provides a good example of the importance of NO for growth regulation. The observation of high levels of NOS seen in mature imaginal discs combined with the observed potential of NO to block cell proliferation suggest that endogenously produced NO might act as a growth arrest agent during the transition to metamorphosis by inhibiting DNA synthesis and supporting cytostasis. This hypothesis is supported by experiments where NOS activity was manipulated in the developing larvae and the resulting changes were monitored in the adult fly. ${ }^{21}$

Suppression of NOS activity in imaginal discs by injection of NOS inhibitors into the developing larvae several hours before metamorphosis, at the end of the third instar, results in a dramatic enlargement of many adult structures: legs, wings, genital structures, tergites and sternites, etc. The changes are most profound in the legs, where the diameter of certain segments increases 3-4-fold (Figure 2). The first and second tarsal segments, tibia and femur, whose primordia had the highest levels of NOS at the larval and prepupal stages are the four leg segments most strongly affected by the inhibition of NOS. The use of

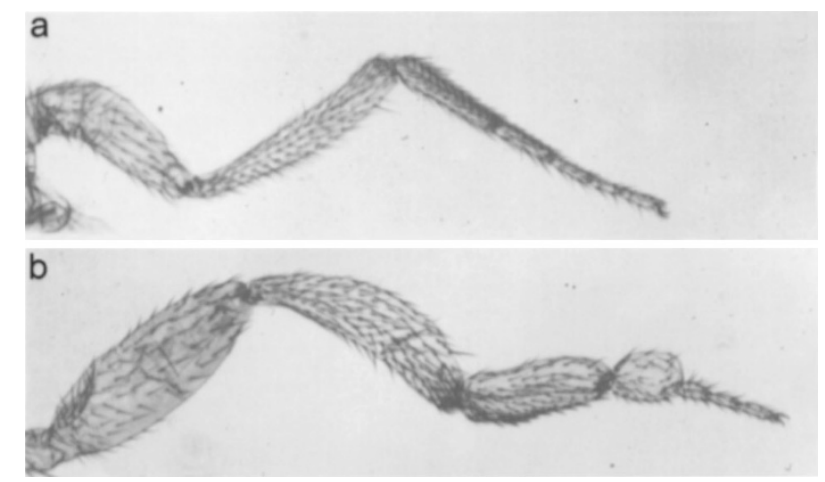

Figure 2 Overgrowth of adult leg segments after inhibition of NOS. (a) Third leg from a control untreated fly. (b) Third leg from a fly treated with NOS inhibitor L-nitroarginine methyl ester at the third instar stage 
structurally unrelated inhibitors of NOS produced similar effects, indicating that the observed changes resulted specifically from blocking NOS activity. When the discs are labeled with 5-bromo-deoxyuridine (BrdU) after inhibition of NOS activity, the number of BrdU-labeled nuclei is significantly increased, suggesting that changing the NO levels directly affects DNA synthesis in the imaginal discs.

In a complementary series of experiments, ectopic expression of NOS was induced in transformed larvae carrying a mouse NOS cDNA transgene under the control of the heat-shock promoter. Changes seen upon treatment of transgenic larvae with heat shock included a reduction in the size of the limbs of the adult fly, supporting the hypothesis that NO acts to suppress cell proliferation in imaginal discs. In extreme cases, the length of the tarsus was halved and several segments were fused together with poorly defined boundaries. The segments of the adult leg most often affected by the overexpression of NOS (third, fourth, and fifth tarsal segments) were those whose precursors exhibited particularly low levels of NOS in the early prepupal stages. BrdU-labeling experiments with treated transgenic larvae support the notion that ectopic expression of NOS affects DNA synthesis: there were markedly fewer BrdU-labeled cells in imaginal discs of treated transgenic larvae, than in untreated controls, in contrast to augmented BrdU-labeling in experiments using NOS inhibitors. Interestingly, the segments of the leg whose size was most often affected when NOS activity was inhibited and the segments that were most often affected when NOS activity was ectopically induced were nonoverlapping and complementary (Figure 3 ). This reciprocal distribution of enlargement and shortening of leg segments in adult flies in response to a decrease or increase in NO matched the distribution of NOS within the leg imaginal discs, thereby supporting the hypothesis that NO plays a causative role in cell cycle arrest in normal development of the fly.

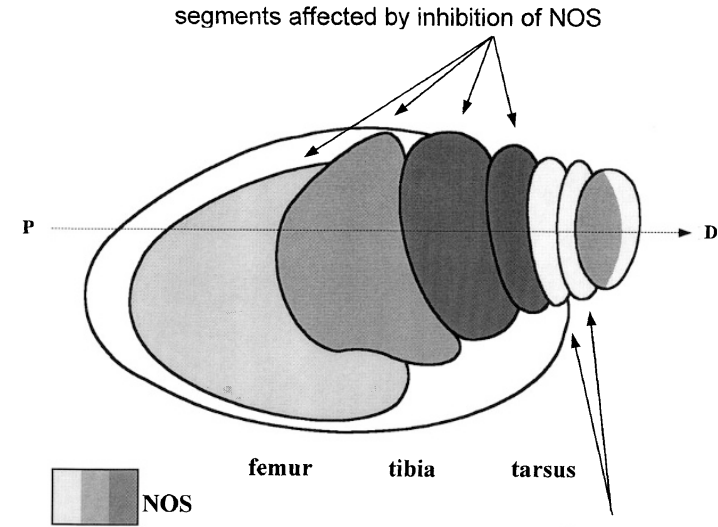

segments affected by ectopic expression of NOS

Figure 3 Changes of the leg segments in adult fly correspond to the distribution of NOS in the imaginal discs of the larvae. Segments that were most often and most strongly affected in adults (enlarged after NOS inhibition and reduced after ectopic NOS expression in larvae) are indicated. 'P-D' marks the proximodistal axis. Shading of the segments on the scheme corresponds approximately to the intensity of NADPH-diaphorase staining
Not all organs of the adult fly are equally affected by inhibition of NOS activity in the larval imaginal discs - for instance, in the eye imaginal disc, there is an increase in the number of cells in S-phase after inhibition of NOS, but in contrast to the leg, the adult eye is apparently unaffected. This is mainly due to programmed cell death counteracting the excessive cell proliferation induced by NOS inhibition: When NOS is inhibited in larvae in which apoptosis in the developing eye is largely prevented by expression of recombinant baculovirus p35 protein under an eye-specific promoter (GMR-P35 flies), ${ }^{46}$ then the number of ommatidia, the repeating unit of the compound Drosophila eye, increases from the nearly invariant complement of 750 in wild-type or untreated GMR-P35 flies, to nearly 820 after NOS inhibition in GMR-P35 flies. In addition, the number of secondary and tertiary pigment cells, cone cells, and bristles, which is increased in GMRP35 flies, is further augmented by inhibition of NOS activity. These experiments show that prevention of apoptosis in the developing Drosophila eyes reveals excessive proliferation of various cell types after NOS inhibition, which is otherwise masked by programmed cell death in the larvae and pupae. These results are remarkable since most of the screens for eye mutations in Drosophila have yielded mutants with a decreased number of cells and ommatidia in the compound eye. This suggests that there is a strict upper limit, which can apparently be exceeded when NOS activity is blocked on the background of suppressed apoptosis. Thus, NO can be involved in affecting the balance between cell proliferation and programmed cell death which determines the final size of an organ.

Although inhibition of NOS leads to hyperproliferation of cells, in most cases no duplications of larger structures (e.g., segments of the legs or wings) is detected. This indicates that the extra proliferation of cells under the influence of NOS inhibitors occurs after determination of the developmental fate of most of the cells in the imaginal disc. This suggests that NO may be more important for the induction of cell cycle arrest and subsequent differentiation of already committed cells than for the initial patterning events involving developmental commitment and establishment of cell identity in the embryo or larvae.

The molecular mechanisms by which NO exerts its antiproliferative activity are uncharacterized. NO is a highly reactive molecule which may interact with and modify a number of potential targets. In addition to guanylate cyclase and ribonucleotide reductase, ${ }^{9,11,12}$ two direct targets of $\mathrm{NO}$, the genes and proteins which mediate the antiproliferative activity of NO may include the components of the retinoblastoma $(\mathrm{Rb})$ pathway such as $\mathrm{p} 21,{ }^{47}$ or cell cycle-dependent kinases (cdks). ${ }^{40}$ In the developing Drosophila eye the $\mathrm{NO}$ and $\mathrm{Rb}$ pathways interact to control the number of cells in the ommatidia, such that manipulations of NOS activity can enhance or suppress the effect of the $\mathrm{Rb}$ and E2F components of the pathway (Kuzin et al. submitted). These data suggest that NO controls precursor cell division in the developing discs by regulating entry into $S$-phase of the cell cycle. A recent screen has revealed that a number of genes which are known to participate in cell cycle control are transcription- 
ally activated after exposure to NO (Nakaya and Enikolopov, unpublished).

\section{NO and synaptogenesis in the developing visual system}

NO signaling is employed at yet another stage of Drosophila development, during the establishment of ordered neuronal connections in the visual system of the fly. During the late larval and early pupal stages of visual system development, the photoreceptor neurons of each ommatidia project to the optic lobe of the brain, with the axons from the outer photoreceptors $(R 1-R 6)$ terminating in the first optic ganglion, the lamina, and with the axons from the inner photoreceptors (R7 and R8) terminating in the deeper layers of the optic lobe, the medulla. ${ }^{48}$ Numerous observations indicate that the construction of the retinotopic map is dependent on retrograde signaling in the optic ganglia. ${ }^{49-51}$ The nature of this retrograde signaling is not well characterized, but recent evidence points to a role for $\mathrm{NO}$ in the establishment of ordered connections by developing neurons.

Throughout the first half of the Drosophila pupal development there is a strong presence of NADPHdiaphorase activity and NOS immunostaining in the neurons of the lamina and medulla ${ }^{22,52}$ (similar strong staining is also seen in lamina and medulla of the locust). ${ }^{53}$ The staining, which is present in the projections but not in the cell bodies, is strongest between 24 and $50 \mathrm{~h}$ after puparium formation (APF). This period corresponds to a discrete temporal window of visual system development when active axon outgrowth from photoreceptors has begun but functional connections with optic lobe interneurons have not yet been established.

Importantly, this period of NOS expression in the optic lobe overlaps with the period when the photoreceptors become sensitive to $\mathrm{NO}$ and can respond to treatment with NO donors by displaying $3^{\prime}, 5^{\prime}$-cyclic guanosine monophosphate (cGMP) immunoreactivity ${ }^{22}$ (when challenged with
NO donors, soluble guanylate cyclase of the photoreceptor cells is activated and produces cGMP which can be detected using specific antibodies). cGMP immunoreactivity is evident in the photoreceptor cell bodies and along the total length of their axons. Different photoreceptors differ in their response to NO, with the axons of the outer cells which terminate in the lamina (R1-R6) being more sensitive and producing stronger cGMP responses to NO than the axons of the inner photoreceptors which terminate in the medulla ( $R 7$ and R8). NO sensitivity lasts from 10 to $50 \mathrm{~h}$ APF, after which the photoreceptors no longer respond to the application of NO donors by synthesizing cGMP. This time window corresponds to the period between the arrival of the photoreceptor axons in the optic lobes and the beginning of the synapse formation between the axons and neuronal projections of the lamina and medulla (Figure 4). Thus, there is a correlation between the time when the photoreceptors' axons respond to NO by synthesizing CGMP and the time when the target neurons in the optic lobe express NOS. Similarly, in the embryonic grasshopper, synaptogenesis correlates with a phase when many identifiable nerve-cell types respond to NO by producing cGMP. ${ }^{54}$ In Drosophila, locust, and grasshopper nervous system preparations, it has been observed that there is very little overlap between the distribution of NADPH-diaphorase-positive cells and cells which display cGMP immunoreactivity in response to $\mathrm{NO},{ }^{22,31,35,53,54}$ suggesting that $\mathrm{NO}$ can act as a transcellular signaling molecule in these insect systems.

The crucial role for NO signals in the formation of a correct retinal projection pattern in Drosophila was demonstrated in vitro using isolated CNS of the pupae. These preparations are capable of undergoing morphological changes mirroring those observed during metamorphosis. When the isolated brain is cultured in the presence of NOS inhibitors or NO scavengers, the optic lobe displays a severely disorganized projection pattern, with retinal axons extending beyond the medulla and into the brain.

\section{Synaptogenesis}

Postsynaptic partners selected

Cartridge formation

5

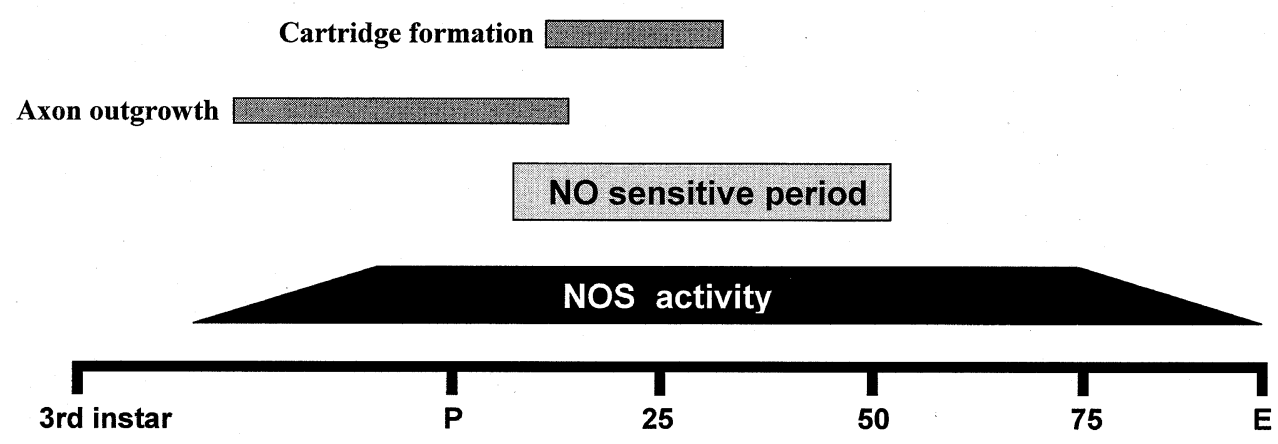

Figure 4 A time line of visual system development in Drosophila. Numbers indicate hours of development after pupariation (P) to adult eclosion (E). The photoreceptors displayed an increase in cGMP immunoreactivity in response to treatment with NO donors for approximately $40 \mathrm{~h}$ during the first half of metamorphosis (light shaded bar). NOS expression is strongly induced at the end of the third instar (black bar); in the optic lobe it is present until $75 \mathrm{~h} \mathrm{APF}$ and is strongest between 24 and $50 \mathrm{~h} \mathrm{APF}$. Time line and scheme are adapted from Gibbs and Truman. ${ }^{22}$ 
Importantly, addition of a cGMP analog suppressed the disruptive effects of NOS inhibitor, suggesting a functional connection between the presence of NOS in the optic lobe neurons and the rise of NO-induced cGMP immunoreactivity in the photoreceptor cells. Furthermore, treatment with inhibitors of guanylate cyclase activity disrupted the retinal projection pattern in a manner similar to the action of NOS inhibitor. This suggests that a NO-cGMP retrograde signaling system is crucial for the proper development of the Drosophila visual system. NOS expression in the lamina may in turn depend on proper retinal innervation, since in the mutants sine oculis and eyes absent which have reduced or absent retinal innervation, NADPHdiaphorase staining of the lamina is significantly suppressed. $^{52}$ In summary, these observations provide strong evidence that NO and cGMP signals act in tandem to stabilize retinal growth cones at the start of synaptic assembly.

The NO sensitivity that occurs during synaptogenesis and synaptic maturation during Drosophila visual system development appears to be conserved among a number of species, suggesting a broad role for $\mathrm{NO}$ in the regulation of process outgrowth and synaptic remodeling during neural development. NO is involved in the pruning of retinotectal synapses in the developing chick visual system. ${ }^{55} \mathrm{NO}$ has been also shown to regulate activity-dependent suppression at the developing neuromuscular junction in Xenopus ${ }^{56}$ and to stimulate the formation of synaptic connections in developing and regenerating rat olfactory neurons. ${ }^{57}$ In the developing visual system of ferrets, inhibition of NO production prevents the proper segregation of retinal ganglion cell projections into distinct layers of the lateral geniculate nucleus, thus suggesting that NO regulates events occurring after axon pathfinding but prior to the establishment of permanent synaptic connections. ${ }^{58}$ These activities of NO during nervous system development may be based on a common property of $\mathrm{NO}$ to induce growth cone collapse which has been demonstrated in vitro for rat dorsal root ganglion neurons ${ }^{59}$ and cultured Xenopus retinal ganglion neurons. ${ }^{60}$

\section{Concluding remarks}

An increasing number of developmental systems provide evidence that the ability of NO to prevent DNA synthesis and cell division is exploited as a part of a developmental program in a variety of tissues. NOS expression and NO synthesis are strongly induced in cultured cells treated with growth factors, and there is increasing evidence that many of the pleiotropic effects of growth factors may be mediated through NO. ${ }^{45,47,61-68}$ NOS levels are also transiently increased during the development of many tissues and organs in mammals, where this transient elevation often coincides with the cessation of division of committed precursor cells. ${ }^{69-73}$ Furthermore, NOS activity is greatly elevated in regenerating tissues. $^{70,71,74-77}$ Together, these studies suggest that in various tissues and cell types, NO may regulate cell differentiation and tissue morphogenesis by acting as endogenous antiproliferative factor. Indeed, NO is crucial for the differentiation of cultured neuronal cells, ${ }^{45,62}$ endothelial cells, ${ }^{63,64,66}$ adipocytes, ${ }^{67}$ osteoblasts, ${ }^{65}$ and myoblasts. ${ }^{78,79}$ Attempts to directly test the function of NOS in mouse development by studying the effects of nNOS gene disruption have so far yielded an incomplete picture: the use of alternate promoters and splice sites leading to the generation of multiple nNOS RNA isoforms during embryonic development ${ }^{24,80-82}$ mask the effect of nNOS gene mutation in the knockout mouse lines. However, it was demonstrated that NO synthesis is essential for the transition from cell proliferation to cell cycle arrest during organ development in Drosophila, ${ }^{21}$ hematopoiesis in mouse (Michurina et al. submitted) and brain development in Xenopus (Peunova et al. submitted). This suggests that NO may act as an essential negative regulator of cell proliferation during tissue differentiation and organ development, controlling the balance between cell proliferation and differentiation in a developing tissue. It may also induce or affect specific traits that characterize the differentiated tissue, thus coupling the exit from the cell cycle to the acquisition of the differentiated phenotype.

$\mathrm{NO}$ is easily diffusible and may therefore exert its antiproliferative effects both in the cell that produces it and its neighbors. Thus, it is possible that NO may induce synchronized changes in a group of adjacent cells and contribute to their coordinated development. Moreover, several adjacent cells producing easily diffusible antiproliferative molecules may share the total pool of these signaling molecules. If a particular threshold level of a signal is needed to initiate a cascade that eventually leads to cell cycle arrest, then the cells in this group could stop dividing when a certain number of cells, and, therefore, a certain local concentration of messenger molecules is reached. This way, by organizing groups of cells into functional clusters, NO may instruct the cells to coordinately terminate their proliferation, when the clusters attain the appropriate size and shape.

\section{Acknowledgments}

We thank Michael Regulski, Yuri Stasiv and Tim Tully for sharing and discussing their unpublished data and commenting on the manuscript. We thank Gerd Bicker and James W. Truman for permission to reproduce their figures. The authors' work was supported by grants from $\mathrm{NIH}$, March of Dimes Foundation, and Charles Henry Leach Foundation.

\section{References}

1. Bryant PJ and Simpson $P$ (1984) Intrinsic and extrinsic control of growth in developing organs. The Quart. Rev. of Biol. 59: 387-415

2. Conlon I and RaffM (1999) Size control in animal development. Cell 96:235-244

3. Raff MC (1996) Size control: the regulation of cell number in animal development. Cell 86: $327-329$

4. Sherr CJ and Roberts JM (1995) Inhibitors of mammalian G1 cyclin-dependent kinases. Genes Devel. 9: 1149-1163

5. Weinberg RA (1995) The retinoblastoma protein and cell cycle control. Cell 81: $323-330$

6. Edgar BA and Lehner CF (1996) Developmental control of cell cycle regulation: a fly's perspective. Science 274: 1646-1652

7. Elledge SJ (1996) Cell cycle checkpoints: preventing an identity crisis. Science 274: $1664-1672$

8. King RW, Deshaies RJ, Peters J-P and Kirschner MC (1996) How proteolysis drives the cell cycle. Science 274: 1652-1659 
9. Bredt DS and Snyder SH (1994) Nitric oxide: a physiologic messenger molecule. Annu. Rev. Biochem. 63: 175-195

10. Nathan C and Xie QW (1994) Nitric oxide synthases: roles, tolls, and controls. Cell 78: $915-918$

11. Stamler JS (1994) Redox signaling: nitrosylation and related target interactions of nitric oxide. Cell 78: $931-936$

12. Garthwaite J and Boulton CL (1995) Nitric oxide signaling in the central nervous system. Annu. Rev. Physiol. 57: 683-706

13. Peunova $\mathrm{N}$ and Enikolopov $\mathrm{G}$ (1993) Amplification of calcium-induced gene transcription by nitric oxide in neuronal cells. Nature 364: $450-453$

14. Haby C, Lisovoski F, Aunis D and Zwiller J (1994) Stimulation of the cyclic GMP pathway by $\mathrm{NO}$ induces expression of the immediate early genes $\mathrm{c}$-fos and junB in PC12 cells. J. Neurochem. 62: 496-501

15. Morris BJ (1995) Stimulation of immediate early gene expression in striatal neurons by nitric oxide. J. Biol. Chem. 270: 24740-24744

16. Pilz RB, Suhasini M, Idriss S, Meinkoth JL and Boss GR (1995) Nitric oxide and cGMP analogs activate transcription from AP-1-responsive promoters in mammalian cells. FASEB J. 9: 552-558

17. Weiss G, Goossen B, Doppler W, Fuchs D, Pantopoulos K, Werner-Felmayer G, Wachter $\mathrm{H}$ and Hentze MW (1993) Translational regulation via iron-responsive elements by the nitric oxide/NO-synthase pathway. EMBO J. 12: 3651-3657

18. Pantopoulos K and Hentze MW (1995) Nitric oxide signaling to iron-regulatory protein: direct control of ferritin mRNA translation and transferrin receptor mRNA stability in transfected fibroblasts. Proc. Natl. Acad. Sci. USA 92: 12671271

19. Kim YM, Son K, Hong SJ, Green A, Chen JJ, Tzeng E, Hierholzer C and Billiar TR (1998) Inhibition of protein synthesis by nitric oxide correlates with cytostatic activity: nitric oxide induces phosphorylation of initiation factor elF-2 alpha. Mol. Med. 4: $179-190$

20. Wang $Y$ and Marsden PA (1995) Nitric oxide synthases: gene structure and regulation. Adv. Pharmacol. 34: 71-90

21. Kuzin B, Roberts I, Peunova N and Enikolopov G (1996) Nitric oxide regulates cell proliferation during Drosophila development. Cell 87: 639-649

22. Gibbs SM and Truman JW (1998) Nitric oxide and cyclic GMP regulate retinal patterning in the optic lobe of Drosophila. Neuron 20: 83-93

23. Regulski M and Tully T (1995) Molecular and biochemical characterization of dNOS: a Drosophila Ca2+/calmodulin-dependent nitric oxide synthase. Proc. Natl. Acad. Sci. USA 92: 9072-9076

24. Brenman JE, Chao DS, Gee SH, McGee AW, Craven SE, Santillano DR, Wu Z, Huang F, Xia H, Peters MF, Froehner SC and Bredt DS (1996) Interaction of nitric oxide synthase with the postsynaptic density protein PSD-95 and alpha1syntrophin mediated by PDZ domains. Cell 84: 757-767

25. Jaffrey SR, Snowman AM, Eliasson MJ, Cohen NA and Snyder SH (1998) CAPON: a protein associated with neuronal nitric oxide synthase that regulates its interactions with PSD95. Neuron 20: 115-124

26. Stott K, Blackburn JM, Butler PJ and Perutz M (1995) Incorporation of glutamine repeats makes protein oligomerize: implications for neurodegenerative diseases. Proc. Natl. Acad. Sci. USA 92: 6509-6513

27. Perutz MF (1999) Glutamine repeats and neurodegenerative diseases: molecular aspects. Trends Biochem. Sci.24: 53-63

28. Muller U (1994) Ca2+/calmodulin-dependent nitric oxide synthase in Apis mellifera and Drosophila melanogaster. Eur. J. Neurosci. 6: 1362-1370

29. Muller U and Bicker G (1994) Calcium-activated release of nitric oxide and cellular distribution of nitric oxide-synthesizing neurons in the nervous system of the locust. J. Neurosci. 14:7521-7528

30. Elphick M, Rayne R, Riveros-Moreno V, Moncada S and Shea M (1995) Nitric oxide synthesis in locust olfactory interneurones. J. Exp. Biol. 198: 821-829

31. Wildemann B and Bicker G (1999) Developmental expression of nitric oxide/ cyclic GMP synthesizing cells in the nervous system of Drosophila melanogaster. J. Neurobiol. 38: 1-15

32. Cohen SM (1993) Imaginal disc development. In: M Bate and A Martinez-Arias, (eds). The Development of Drosophila melanogaster. Cold Spring Harbor Laboratory Press, Cold Spring Harbor, NY, 747-841

33. Muller U and Buchner E (1993) Histochemical localization of NADPH diaphorase in the adult Drosophila brain. Is nitric oxide a neuronal messenger also in insects? Naturwissenschaften 80: 524-526

34. Muller U (1997) The nitric oxide system in insects. Prog. Neurobiol. 51: $363-$ 381

35. Bicker G (1998) NO news from insect brains. Trends Neurosci. 21: 349-355
36. Garg UC and Hassid A (1989) Nitric oxide-generating vasodilators and 8-bromocyclic guanosine monophosphate inhibit mitogenesis and proliferation of cultured rat vascular smooth muscle cells. J. Clin. Invest. 83: 1774-1777

37. Lepoivre M, Chenais B, Yapo A, Lemaire G, Thelander L and Tenu JP (1990) Alterations of ribonucleotide reductase activity following induction of the nitritegenerating pathway in adenocarcinoma cells. J. Biol. Chem. 265: 14143-14149

38. Kwon NS, Stuehr DJ and Nathan CF (1991) Inhibition of tumor cell ribonucleotide reductase by macrophage-derived nitric oxide. J. Exp. Med. 174: 761-767

39. Sarkar R, Gordon D, Stanley JC and Webb RC (1997) Cell cycle effects of nitric oxide on vascular smooth muscle cells. Am. J. Physiol. 272: H1810-H1818

40. Ishida A, Sasaguri T, Kosaka C, Nojima H and Ogata J (1997) Induction of the cyclin-dependent kinase inhibitor p21(Sdi1/Cip1/Waf1) by nitric oxidegenerating vasodilator in vascular smooth muscle cells. J. Biol. Chem. 272: $10050-10057$

41. Messmer UK, Ankarcrona M, Nicotera $P$ and Brune B (1994) p53 expression in nitric oxide-induced apoptosis. FEBS Lett. 355: 23-26

42. Forrester K, Ambs S, Lupold SE, Kapust RB, Spillare EA, Weinberg WC, FelleyBosco E, Wang XW, Geller DA, Tzeng E, Billiar TR and Harris CC (1996) Nitric oxide-induced p53 accumulation and regulation of inducible nitric oxide synthase expression by wild-type p53. Proc. Natl. Acad. Sci. USA 93: 24422447

43. Messmer UK and Brune B (1996) Nitric oxide-induced apoptosis: p53dependent and p53-independent signalling pathways. Biochem. J. 319: 299305

44. Takagi K, Isobe Y, Yasukawa K, Okouchi E and Suketa Y (1994) Nitric oxide blocks the cell cycle of mouse macrophage-like cells in the early $\mathrm{G} 2+\mathrm{M}$ phase. FEBS Lett. 340: 159-162

45. Peunova Nand Enikolopov G (1995) Nitric oxide triggers a switch to growth arrest during differentiation of neuronal cells. Nature 375: 68-73

46. Hay BA, Wolff T and Rubin GM (1994) Expression of baculovirus P35 prevents cell death in Drosophila. Development 120: 2121-2129

47. Poluha W, Schonhoff CM, Harrington KS, Lachyankar MB, Crosbie NE, Bulseco DA and Ross AH (1997) A novel, nerve growth factor-activated pathway involving nitric oxide, $\mathrm{p} 53$, and $\mathrm{p} 21 \mathrm{WAF} 1$ regulates neuronal differentiation of $\mathrm{PC} 12$ cells. J. Biol. Chem. 272: 24002-24007

48. Meinertzhagen IA and Hanson TE (1993) The development of the optic lobe. In: M Bate and A Martinez-Arias (eds). The Development of Drosophila melanogaster. Cold Spring Harbor Laboratory Press, Cold Spring Harbor, NY, $1363-1491$

49. Kunes S and Steller H (1993) Topography in the Drosophila visual system. Curr. Opin. Neurobiol. 3: 53-59

50. Ashley JA and Katz FN (1994) Competition and position-dependent targeting in the development of the Drosophila R7 visual projections. Development 120: $1537-1547$

51. HuangZand KunesS (1996) Hedgehog, transmittedalong retinal axons, triggers neurogenesis in the developing visual centers of the Drosophila brain. Cell 86: 411-422

52. Atkinson Jand Panni MK (1999) Optictarget regulation of NADPH-diaphorase by larval retinal axons in Drosophila. Neurosci. Lett. 262: 21-24

53. Bicker $G$ and Schmachtenberg O (1997) Cytochemical evidence for nitric oxide/ cyclic GMP signal transmission in the visual system of the locust. Eur. J. Neurosci. 9: 189-193

54. Truman JW, De Vente J and Ball EE (1996) Nitric oxide-sensitive guanylate cyclase activity is associated with the maturational phase of neuronal development in insects. Development 122: 3949-3958

55. Wu HH, Williams CV and McLoon SC (1994) Involvement of nitric oxide in the elimination of a transient retinotectal projection in development. Science 265: $1593-1596$

56. Wang T, Xie Z and Lu B (1995) Nitric oxide mediates activity-dependent synaptic suppression at developing neuromuscular synapses. Nature 374: 262-266

57. Roskams AJ, Bredt DS, Dawson TM and Ronnett GV (1994) Nitric oxide mediates the formation of synaptic connections in developing and regenerating olfactory receptor neurons. Neuron 13: 289-299

58. Cramer KS, Angelucci A, Hahm JO, Bogdanov MB and Sur M (1996) A role for nitric oxide in the development of the ferret retinogeniculate projection. $\mathrm{J}$. Neurosci. 16: 7995-8004

59. Hess DT, Patterson SI, Smith DS and Skene JH (1993) Neuronal growth cone collapse and inhibition of protein fatty acylation by nitric oxide. Nature 366: $562-$ 565 
60. Renteria RC and Constantine-Paton M (1996) Exogenous nitric oxide causes collapse of retinal ganglion cell axonal growth cones in vitro. J. Neurobiol. 29: $415-428$

61. Peunova N, Kuzin B, Roberts I, O'Kane C and Enikolopov G (1996) Nitric oxide, cell multiplication, and cell survival. Cold Spring Harb. Symp. Quant. Biol. 61: 417-426

62. Obregon E, Punzon MC, Gonzalez-Nicolas J, Fernandez-Cruz E, Fresno M and Munoz-Fernandez MA (1997) Induction of adhesion/differentiation of human neuroblastoma cells by tumornecrosis factor-alpha requires the expression of an inducible nitric oxide synthase. Eur. J. Neurosci. 9: 1184-1193

63. Papapetropoulos A, Desai KM, Rudic RD, Mayer B, Zhang R, Ruiz-Torres MP, Garcia-Cardena G, Madri JA and Sessa WC (1997) Nitric oxide synthase inhibitors attenuate transforming-growth-factor beta 1-stimulated capillary organization in vitro. Am. J. Pathol. 150: 1835-1844

64. Papapetropoulos A, Garcia-Cardena G, Madri JA and Sessa WC (1997) Nitric oxide production contributes to the angiogenic properties of vascular endothelial growth factor in human endothelial cells. J. Clin. Invest. 100: 3131-3139

65. Hikiji H, Shin WS, Oida S, Takato T, Koizumi T and Toyo-oka T (1997) Direct action of nitric oxide on osteoblastic differentiation. FEBS Lett. 410: 238-242

66. Babaei S, Teichert-Kuliszewska K, Monge JC, Mohamed F, Bendeck MP and Stewart DJ (1998) Role of nitric oxide in the angiogenic response in vitro to basic fibroblast growth factor. Circ. Res. 82: 1007-1015

67. Nisoli E, Clementi E, Tonello C, Sciorati C, Briscini L and Carruba MO (1998) Effects of nitric oxide on proliferation and differentiation of rat brown adipocytes in primary cultures. Br. J. Pharmacol. 125: 888-894

68. Heneka MT, Loschmann PA, Gleichmann M, Weller M, Schulz JB, Wullner U and Klockgether T (1998) Induction of nitric oxide synthase and nitric oxide-mediated apoptosis in neuronal PC12 cells after stimulation with tumor necrosis factoralpha/lipopolysaccharide. J. Neurochem. 71: 88-94

69. Bredt DS and Snyder SH (1994) Transient nitric oxide synthase neurons in embryonic cerebral cortical plate, sensory ganglia, and olfactory epithelium. Neuron 13: 301-313

70. Blottner D, Grozdanovic Z and Gossrau R (1995) Histochemistry of nitric oxide synthase in the nervous system. Histochem. J. 27: 785-811
71. Collin-Osdoby P, Nickols GA and Osdoby P (1995) Bone cell function, regulation and communication: a role for nitric oxide. J. Cell. Biochem. 57: 399-408

72. Shaul PW (1995) Nitric oxide in the developing lung. Adv. Pediatr. 42: $367-414$

73. Wetts R, Phelps PE and Vaughn JE (1995) Transient and continuous expression of NADPH diaphorase in different neuronal populations of developing rat spinal cord. Dev. Dyn. 202: 215-228

74. Decker KF and Obolenskaya MY (1995) Cytokines, nitric oxide synthesis and liver regeneration. J. Gastroenterol. Hepatol. 10 (Suppl 1): S12-S17

75. Hortelano S, Dewez B, Genaro AM, Diaz-Guerra MJ and Bosca L (1995) Nitric oxide is released in regenerating liver after partial hepatectomy. Hepatology 21 : $776-786$

76. Bruch-Gerharz D, Ruzicka T and Kolb-Bachofen V (1998) Nitric oxide and its implications in skin homeostasis and disease - a review. Arch. Dermatol. Res. 290: 643-651

77. Poppa V, Miyashiro JK, Corson MA and Berk BC (1998) Endothelial NO synthase is increased in regenerating endothelium after denuding injury of the rat aorta. Arterioscler. Thromb. Vasc. Biol. 18: 1312-1321

78. Lee KH, Kim DG, Shin NY, Song WK, Kwon H, Chung CH and Kang MS (1997) NF-kappaB-dependent expression of nitric oxide synthase is required for membrane fusion of chick embryonic myoblasts. Biochem. J. 324: 237-242

79. Kim SS, Rhee S, Lee KH, Kim JH, Kim HS, Kang MS and Chung CH (1998) Inhibitors of the proteasome block the myogenic differentiation of rat L6 myoblasts. FEBS Lett. 433: 47-50

80. Brenman JE, Xia H, Chao DS, Black SM and Bredt DS (1997) Regulation of neuronal nitric oxide synthase through alternative transcripts. Dev. Neurosci. 19: $224-231$

81. Lee MA, Cai L, Hubner N, Lee YA and Lindpaintner K (1997) Tissue- and development-specific expression of multiple alternatively spliced transcripts of rat neuronal nitric oxide synthase. J. Clin. Invest. 100: 1507-1512

82. Eliasson MJ, Blackshaw S, Schell MJ and Snyder SH (1997) Neuronal nitric oxide synthase alternatively spliced forms: prominent functional localizations in the brain. Proc. Natl. Acad. Sci. USA 94: 3396-3401 